\title{
Improving the blast resistance of the elite rice variety Kongyu- 131 by updating the pi21 locus
}

\author{
Xiaomin Feng ${ }^{1,2,3}$, Kangxue Lin ${ }^{1,3}$, Wenqi Zhang ${ }^{1,3}$, Jianzong Nan ${ }^{1,3}$, Xiaohui Zhang ${ }^{1,3}$, Chen Wang ${ }^{1,3}$,
} Rongsheng Wang ${ }^{1,3}$, Guoqiang Jiang ${ }^{1}$, Qingbo Yuan ${ }^{1}$ and Shaoyang Lin ${ }^{1,3^{*}}$

\begin{abstract}
Background: As an elite japonica rice variety, Kongyu-131 has been cultivated for over 20 years in the third accumulated temperature zone of Heilongjiang Province, China. However, the cultivated area of Kongyu-131 has decreased each year due to extensive outbreaks of rice blast. To achieve the goals of improving blast resistance and preserving other desirable traits in Kongyu-131, a genome-updating method similar to repairing a bug in a computer program was adopted in this study. A new allele of the broad-spectrum blast resistance gene pi21 in the upland rice variety GKGH was mined by genetic analysis and introgressed into the genome of Kongyu-131 to upgrade its blast resistance.

Result: QTL analysis was performed with an $F_{2}$ population derived from a cross between Kongyu-131 and GKGH, and a blast resistance QTL was detected near the pi21 locus. Parental Pi21 sequence alignment showed that the pi21 of the donor (GKGH) was a new allele. By 5 InDel or SNP markers designed based on the sequence within and around pi21, the introgressed chromosome segment was shortened to less than $634 \mathrm{~kb}$ to minimize linkage drag by screening recombinants in the target region. The RRPG was 99.92\%, calculated according to 201 SNP markers evenly distributed on 12 chromosomes. Artificial inoculation at the seedling stage showed that the blast resistance of the new Kongyu-131 was improved significantly. Field experiments also indicated that the improved Kongyu-131 had enhanced field resistance to rice blast and grain-quality traits similar to those of the original Kongyu-131.
\end{abstract}

Conclusions: It is feasible to improve resistance to rice blast and preserve other desirable traits by precisely improving the Pi21 locus of Kongyu-131. Linkage drag can be eliminated effectively via recombinant selection on both sides of the target gene.

Keywords: Rice, Blast resistance, SNP marker, Pi21, Linkage drag

\section{Background}

Rice blast caused by the fungus Magnaporthe oryzae is a worldwide rice disease that generally causes a serious reduction in rice yield. The global annual crop loss due to blast was estimated to be $\$ 66$ billion, representing enough rice to feed 60 million people [1]. Rice blast is a major factor limiting rice yield and affects its grain quality. It is widely accepted that cultivating disease-resistant

\footnotetext{
* Correspondence: sylin@genetics.ac.cn

${ }^{1}$ State Key Laboratory of Plant Genomics, Institute of Genetics and Developmental Biology, Chinese Academy of Sciences, Beijing 100101, China

${ }^{3}$ University of Chinese Academy of Sciences, Beijing 100039, China
}

Full list of author information is available at the end of the article varieties is the most economical and effective control method.

Discovering and utilizing blast resistance genes are the premises of disease resistance breeding. To date, more than 100 major blast R-genes have been identified. These genes are distributed on all 12 chromosomes of rice, and more than half are concentrated on chromosomes 6, 11 and 12 [2]. Since Wang et al. cloned the first rice blast resistance gene $P i b$ [3], more than 30 rice blast resistance genes have been cloned [2]. Except for $b s r-d 1$ [4], $b s r-k 1$ [5], Pid2 [6], pi21 [7] and Ptr [8], the blast resistance genes all encode NBS-LRR proteins. Pi21 was the first cloned recessive blast resistance QTL, encoding a proline-rich

(c) The Author(s). 2019 Open Access This article is distributed under the terms of the Creative Commons Attribution 4.0 International License (http://creativecommons.org/licenses/by/4.0/), which permits unrestricted use, distribution, and reproduction in any medium, provided you give appropriate credit to the original author(s) and the source, provide a link to the Creative Commons license, and indicate if changes were made. The Creative Commons Public Domain Dedication waiver (http://creativecommons.org/publicdomain/zero/1.0/) applies to the data made available in this article, unless otherwise stated. 
protein that includes a putative heavy metal-binding domain and putative protein-protein interaction motifs [7]. Compared with the susceptible varieties, the variety Owarihatamochi contains $21 \mathrm{bp}$ and $48 \mathrm{bp}$ deletions in the proline-rich motif that lead to an increase in resistance [7]. Cloning of blast resistance genes/QTLs, the discovery of excellent alleles and the elucidation of molecular mechanisms have provided favorable gene resources and a theoretical basis for rice blast resistance breeding.

Conventional breeding for disease resistance combines field phenotype selection and resistance identification to introduce resistance genes by crossing and backcrossing, which is still commonly used in disease resistance breeding. However, the resistance gene is often lost in the process of breeding, which causes low breeding efficiency and a long breeding cycle. With the development of molecular biology and the identification of increasing numbers of blast resistance genes, molecular breeding implementing molecular marker technology has become an important part of plant breeding.

Marker-assisted selection (MAS) can make up for the deficiency of conventional breeding for disease resistance. Combined with conventional breeding methods, MAS has been used to improve resistance to rice blast and bacterial leaf blight [9-11]. However, molecular breeding technology with MAS still has some shortcomings. First, MAS uses DNA markers linked to target genes to indirectly select the target traits. Recombination between the linked markers and target genes can affect the selection accuracy. Second, the introduction of the target gene by MAS can also introduce some unwanted genes, which causes linkage drag. Third, after introducing the target gene by MAS, selection for other traits mainly relies on the field phenotype, which usually causes the loss of some other excellent traits and an unclear genetic background. Solving these problems will help make molecular breeding more accurate and efficient.

Owing to a series of advantages such as early maturity, high quality, high yield, cold tolerance and wide adaptability, Kongyu-131 has been cultivated in over 8 million hectares since its introduction [12]. However, the largescale planting of Kongyu-131 over decades resulted in a change in the $M$. oryzae population structure and the emergence of dominant virulent strains, which eventually caused an outbreak of blast disease and substantial economic loss. It is unfortunate that Kongyu-131, a precious germplasm resource, had to be withdrawn from production simply because of its susceptibility to rice blast [12]. By resequencing the genome of Kongyu-131 and comparing it with cloned R-gene sequences, Zhang et al. found that Kongyu-131 lacked almost all the Rgenes except for Pish [13]. By using the principle of genome updating described by Feng et al. [14], we mined a favorable blast resistance gene module (a small chromosome segment hosting a superior pi21 allelic variant from a blast-resistant upland variety) to improve the blast resistance of Kongyu-131 in this study.

\section{Results}

\section{Marker-trait association analysis}

Genetic analysis was performed by using an $F_{2}$ population derived form Kongyu-131 and GKGH with 141 individuals. The result indicated that the marker tightly linked to pi21 was significantly associated with LD and explained $16.4 \%$ of the phenotypic variation (Table 1 ). The number of lines with the three genotypic classes at the pi21 locus (Kongyu-131-homozygous, heterozygous, and GKGH-homozygous genotypes) was 33, 75 and 33, respectively, which showed a good fit to the expected 1 : $2: 1$ ratio based on a chi-square test $\left(x^{2}=0.57, p>0.75\right)$. The frequency distribution for the LD of the three genotypic classes at the pi21 locus is shown in Fig. 1a. The GKGH-homozygous lines all showed resistance to blast disease, while the LD of both the Kongyu-131homozygous lines and the heterozygotes ranged from 0 to 9. The average phenotypic value of the GKGHhomozygous lines was significantly lower than that of Kongyu-131, but no difference was observed between the Kongyu-131-homozygous lines and the heterozygote (Fig. 1b).

\section{Comparison of pi2 1 alleles in different rice parents}

The pi21 sequences of Kongyu-131, GKGH, Aichi-asahi and Owarihatamochi were compared. The resistant pi21 allele had deletions of $15 \mathrm{bp}$ and $33 \mathrm{bp}$ compared to the susceptible Pi21 allele in the second exon, corresponding to $21 \mathrm{bp}$ and $48 \mathrm{bp}$ deletions at the same position in a previous report [7]. These results showed that the pi21 allele in GKGH was a new haplotype. In contrast to the Aichi-asahi allele, the Kongyu-131 allele exhibited a nucleotide change resulting in amino acid variation (Gln to Pro) in the second exon (Fig. 2).

\section{Foreground selection, recombinant selection, background selection and chromosome composition evaluation}

Two lines selected from $\mathrm{BC}_{2} \mathrm{~F}_{1}$ population were crossed with Kongyu-131 to produce $92 \mathrm{BC}_{3} \mathrm{~F}_{1}$ lines, from which a line named $\mathrm{BC}_{3} \mathrm{~F}_{1}-08 \mathrm{G} 02$ in heterozygous form at the InDel3 locus, with recombination on one side (between SNP1 and SNP2) of the target gene, was selected. Selfing was performed to produce $190 \mathrm{BC}_{3} \mathrm{~F}_{2}$ lines, and a line named $\mathrm{BC}_{3} \mathrm{~F}_{2}-669 \mathrm{E} 10$, which hosted the target gene and exhibited recombination on the other side (between SNP4 and SNP5), was selected. According to the sequence difference between Kongyu-131 and GKGH, 201 SNP markers evenly distributed on all 12 chromosomes were used to detect the genetic background. The 
Table 1 QTL for blast resistance in the $F_{2}$ population

\begin{tabular}{lclcccc}
\hline Traits & Chr & Linked R-gene & Additive effect & Dominant effect & LOD & Var (\%) \\
\hline LD & 4 & pi21 & -2.9 & 0.5 & 5.5 & $16.40 \%$
\end{tabular}

Additive effect, Dominant effect and LOD were calculated according to the tightly linked SNP marker of pi21. Var (\%) indicates the percentage of total phenotypic variance explained by the QTL

results showed that in addition to the target segment, 5 nontarget segments, including two homozygous segments on chromosomes 2 and 12, were in the background, and the RRPG was 95.59\% (Fig. 3a).

To remove the nontarget segments, $\mathrm{BC}_{3} \mathrm{~F}_{2}-669 \mathrm{E} 10$ was crossed with Kongyu- 131 to produce the $\mathrm{BC}_{4} \mathrm{~F}_{1}$ generation with 33 plants, from which a line named $\mathrm{BC}_{4} \mathrm{~F}_{1}$ 30B07 was selected by using the markers in heterozygous form in $\mathrm{BC}_{3} \mathrm{~F}_{2}-669 \mathrm{E} 10$ to genotype the $\mathrm{BC}_{4} \mathrm{~F}_{1}$ population. In addition to the target segment, $\mathrm{BC}_{4} \mathrm{~F}_{1}$ 30B07 hosted 3 nontarget segments on chromosomes 1 , 2 and 12, with an RRPG of $98.02 \%$ (Fig. 3b). To further remove nontarget segments and obtain the improved line hosting only a very small homozygous segment with a target gene, $\mathrm{BC}_{4} \mathrm{~F}_{2}-350 \mathrm{E} 03$ was selected from 948 selfing progenies of $\mathrm{BC}_{4} \mathrm{~F}_{1}-30 \mathrm{~B} 07$. The length of the target introgression segment in the improved line $\mathrm{BC}_{4} \mathrm{~F}_{2}-$ 350E03 was less than $634 \mathrm{~kb}$, and the RRPG was $99.92 \%$ based on 201 SNP markers (Fig. 3c).

The resistance of the improved line $\mathrm{BC}_{4} \mathrm{~F}_{2}-350 \mathrm{E} 03$ to leaf blast at the seedling stage increased significantly

To test the blast resistance effect of the introgressed pi21 allele from GKGH, two parents and the improved line $\mathrm{BC}_{4} \mathrm{~F}_{2}-350 \mathrm{E} 03$ were inoculated with 7 strains isolated from the diseased panicles or leaves of Kongyu-131 at the seedling stage. The results showed that Kongyu131 was susceptible or highly susceptible to all 7 strains, while the single point substitution line (SPSL) $\mathrm{BC}_{4} \mathrm{~F}_{2}-$ 350E03 showed different degrees of resistance to these 7 strains and a resistance level similar to that of the donor parent (GKGH) (Fig. 4, Table 2). The results indicated that the segment hosting the resistant pi21 allele from the donor (GKGH) significantly improved the blast resistance of Kongyu-131 to the 7 strains from Heilongjiang Province.

\section{No significant difference in agronomic traits was observed between Kongyu-131 and the improved line $\mathrm{BC}_{4} \mathrm{~F}_{2}-350 \mathrm{E03}$}

The plant architectures of Kongyu-131 and the improved line $\mathrm{BC}_{4} \mathrm{~F}_{2}-350 \mathrm{E} 03$ in Beijing and Jiamusi are shown in Fig. 5, and the comparison of agronomic traits is shown in Table 3. In Beijing, the DTH of the SPSL was 2.7 days later than that of Kongyu-131, while other traits such as PH, YP, SSP and TGW of the improved line were similar to those of Kongyu-131. In Jiamusi in 2017 and 2018, no significant difference was observed
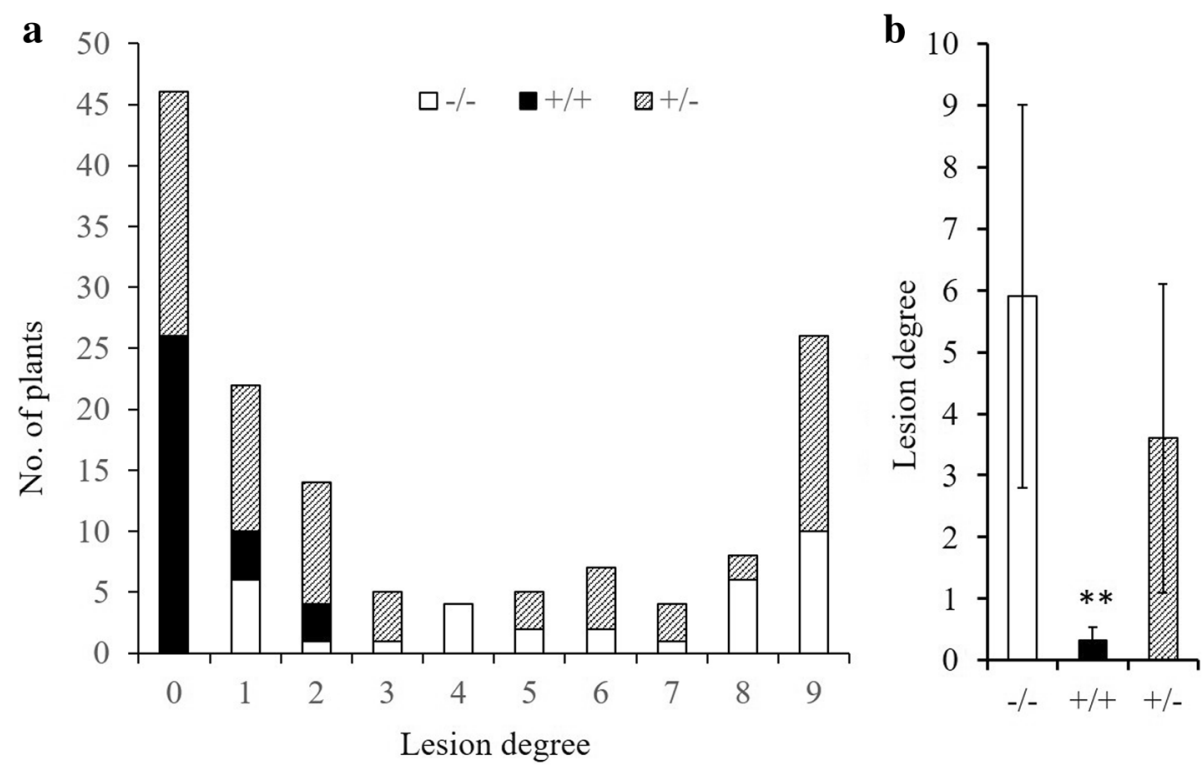

Fig. 1 Marker-trait association analysis of the $F_{2}$ population. a Frequency distribution of lesion degree in the $F_{2}$ population. b Comparison of lesion degree among the three genotypic classes of the Pi21 locus in the $F_{2}$ population. Data was presented as the means \pm SD (standard deviations). -/- represents Kongyu-131-homozygous lines, +/- represents the heterozygote, and +/+ represents GKGH-homozygous lines. **above the bar chart represents a significant difference based on Student's $t$-test at $p \leq 0.01$ 


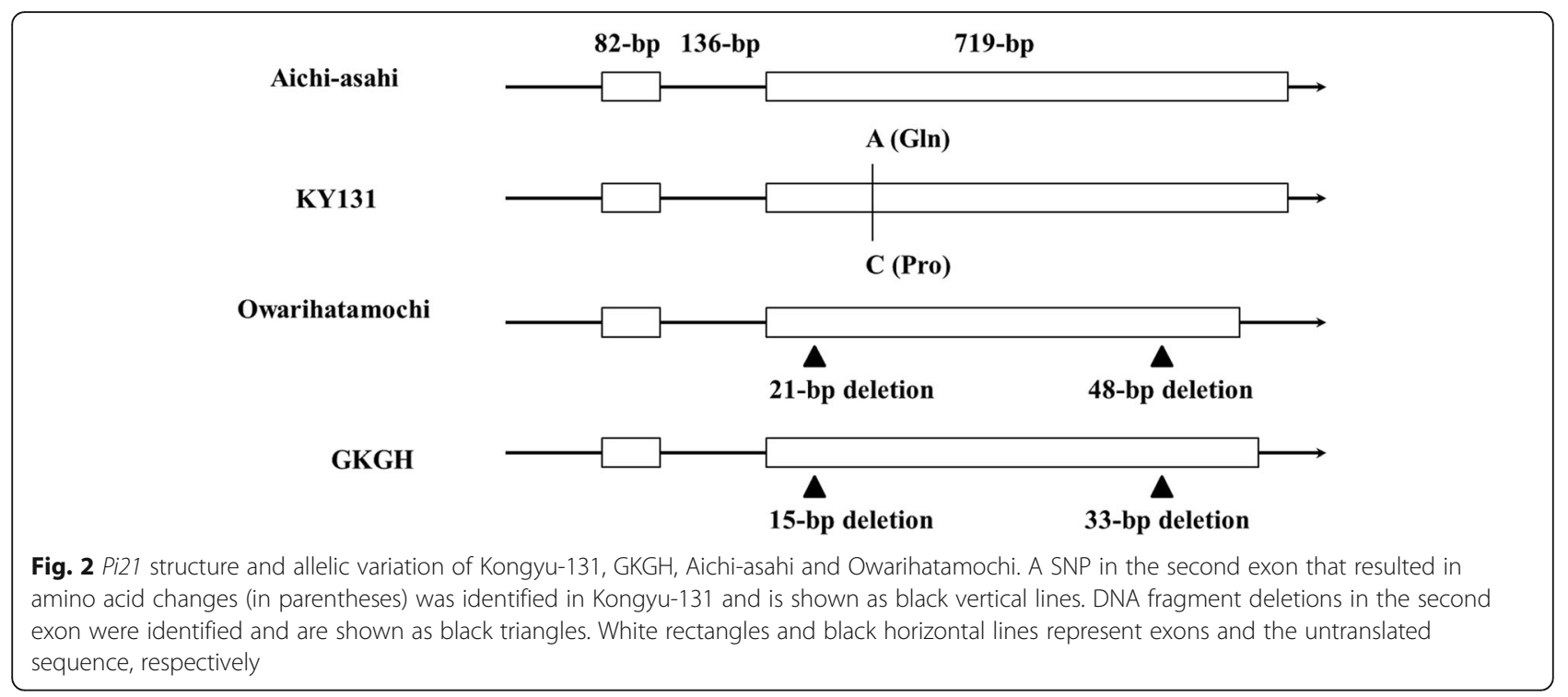

for important agronomic traits such as DTH, PH, SSP, YP and TGW between the improved line and Kongyu131. However, the GYP of the improved line was significantly higher than that of Kongyu-131 because some plants of Kongyu-131 were infected with rice blast, while the improved line was free from blast disease. These results indicated that the introgression of the resistant pi21 allele from the donor parent significantly improved the field blast resistance of Kongyu-131.

\section{The quality traits of the improved line were similar to those of Kongyu-131}

To determine whether the improved line retained the original high-quality characters, we first compared the appearance quality traits, namely, KL, KW, LWR and CKR, to those of Kongyu-131 (Fig. 6). The improved line exhibited appearance quality traits similar to those of Kongyu-131 in the same location (Fig. 6a-f). However, the CKRs of the improved line and Kongyu-131 in Beijing were both significantly higher than in Jiamusi (Fig. 6f). Then, we compared the cooking quality, namely, the AC and ASV, of the improved line to that of Kongyu-131 (Fig. 6g, h). No significant differences in AC and ASV were detected between the lines at the same location. However, the AC and ASV of both the improved line and Kongyu-131 in Beijing were significantly lower than those in Jiamusi.

\section{Discussion}

The large rice blast outbreak in the paddy fields where the elite cultivar Kongyu-131 is cultivated has led to the gradual withdrawal of this cultivar from production. It is challenging to use a blast-resistant upland rice variety as the donor parent to improve the blast resistance of Kongyu-131 and avoid changing other desirable characteristics. Therefore, we tried a precise and targeted genome-updating method $[15,16]$, namely, only updating the susceptible Pi21 locus in the Kongyu-131 genome, to improve the blast resistance of this cultivar. Ultimately, the updated Kongyu-131 hosting the resistance allele of pi21 from the donor parent GKGH exhibited high blast resistance. Moreover, the results of the field experiment showed that the agronomic characteristics and quality traits of the updated Kongyu-131 in Beijing and Jiamusi were similar to those of the original Kongyu-131.

The genetic analysis results in $\mathrm{F}_{2}$ population were consistent with pi21 being a recessive rice blast resistance gene. But the total number of heterozygotes shown resistance to blast disease (with LD of $0-3$ ) even exceeded that of GKGH-homozygous lines (Fig. 1). This could be explained by the existence of other unidentified blast resistance genes in the genetic background or it is possible that some plants may be just escaped during the disease test. CKRs of the improved line and Kongyu-131 in Beijing were both significantly higher than in Jiamusi (Fig. 6f), this result may be explained by the fact that the latitude of the Beijing area was not in the suitable zone for the cultivation of Kongyu-131, and the high accumulated temperature caused early flowering and rapid, insufficient grain filling of Kongyu-131.

\section{From field selection by phenotype to indoor selection by genotype}

Traditional breeding of rice disease resistance mainly relied on phenotype selection according to comprehensive field characteristics, including resistance performance, which usually caused the loss of resistance genes during the breeding process. In addition, identification results were easily affected by the environment, and field 


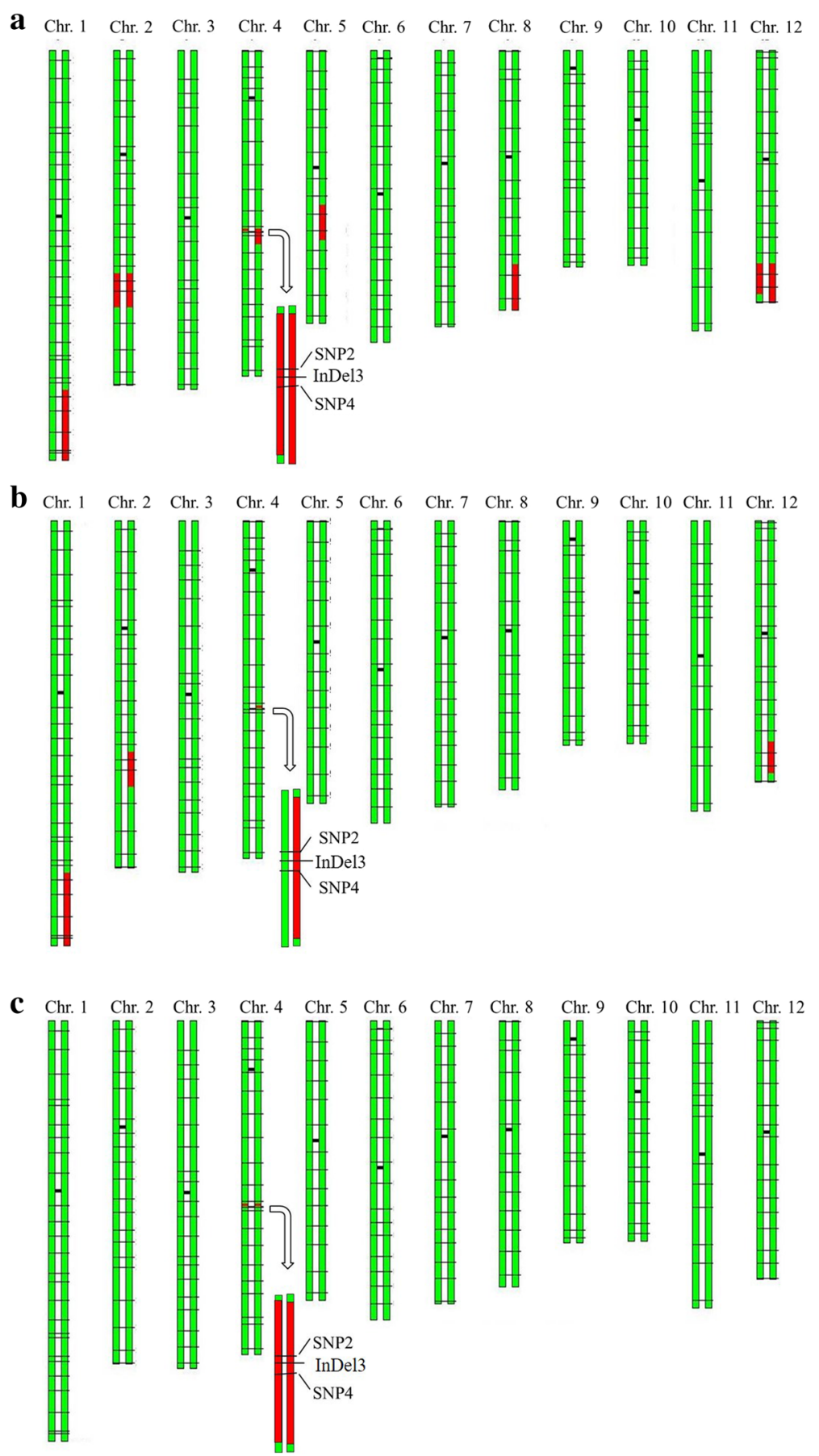

Fig. 3 Graphical genotype of the selected lines. a $\mathrm{BC}_{3} \mathrm{~F}_{2}-669 \mathrm{E} 10$. $\mathbf{b} \mathrm{BC}_{4} \mathrm{~F}_{1}-30 \mathrm{~B} 07 . \mathbf{c} \mathrm{BC}_{4} \mathrm{~F}_{2}-350 \mathrm{E} 03$. The green bars represent the chromosome fragments derived from Kongyu-131, the red bars represent the chromosome fragments derived from GKGH, and the horizontal black lines indicate the SNP markers (the shorter, darker lines represent the centromeres)

selection was constrained by the individual developmental stage, which led to low selection accuracy and efficiency. Instead of traditional breeding, in this study, after determining that the donor parent GKGH contained the superior pi21 allele, foreground selection, recombinant selection and background selection were performed to select suitable plants using 201 SNP markers, including SNP1-SNP5, at the seedling stage. Selection based on genotype was used as a substitute for field phenotype selection, which made the selection results reliable and independent of environmental impact. 


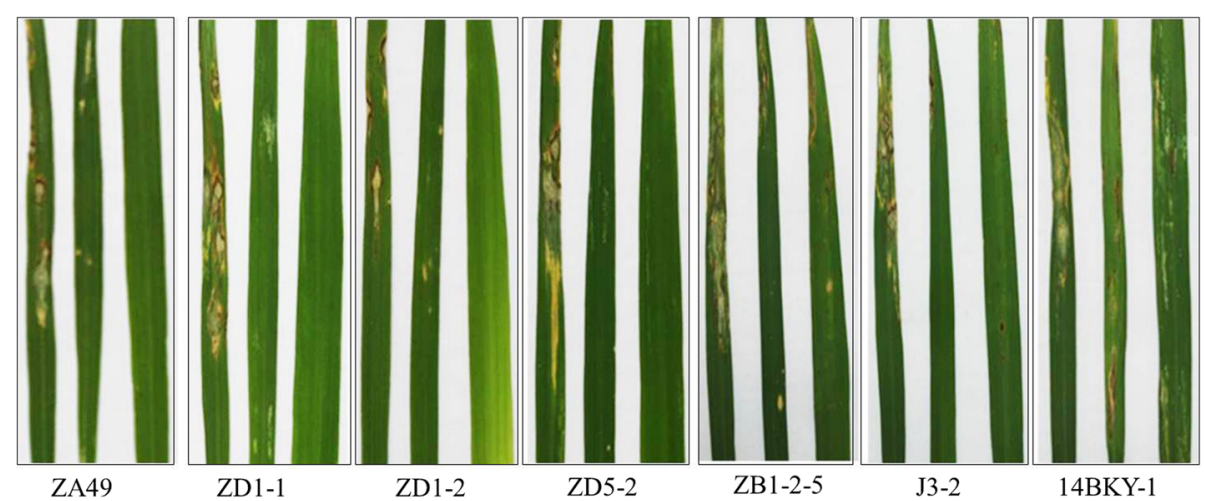

Fig. 4 The artificial inoculation results for Kongyu-131, the donor and the improved line $\mathrm{BC}_{4} \mathrm{~F}_{2}-350 \mathrm{E} 03$ with the 7 strains of $M$. oryzae at the seedling stage: Kongyu-131 (left), $\mathrm{BC}_{4} \mathrm{~F}_{2}-350 \mathrm{E} 03$ (middle), and GKGH (right)

\section{Hastening the RRPG and removing linkage drag}

Targeted improvement of an undesirable trait has always been the goal of breeders. However, due to technical limitations, traditional breeding methods often lose some other desirable traits while improving target traits. An unknown genetic background makes the goal of only improving the undesirable trait hard to realize. In this study, the background was detected by 201 SNP markers evenly distributed throughout the genome to screen out the individuals with the target gene and highest RRPG. Then, the selected lines were crossed with Kongyu-131 to accelerate the RRPG. In addition to backcrossing, this study also used the principle of selfing separation to speed up the RRPG and shorten breeding time. After 5 crosses and two self-crosses combined with selection by genotype, the improved line $\mathrm{BC}_{4} \mathrm{~F}_{2}-350 \mathrm{E} 03$ was finally selected with the resistant pi21 allele from the donor parent GKGH, and the RRPG reached 99.92\%.

The target chromosome segment was shortened to less than $634 \mathrm{~kb}$ via two rounds of recombinant selection on both sides of the pi21 locus. The actual size of the introduced segment should be further confirmed by adding

Table 2 The artificial inoculation results for Kongyu-131, the donor and the SPSL BC $\mathrm{F}_{2}-350 \mathrm{E} 03$ with the 7 isolates of $\mathrm{M}$. grisea at the seedling stage

\begin{tabular}{llll}
\hline Isolate & & \multicolumn{2}{l}{ Lesion degree } \\
\cline { 3 - 4 } & KY131 & $\mathrm{BC}_{4} \mathrm{~F}_{2}-350 \mathrm{E} 03$ & $\mathrm{GKGH}$ \\
\hline ZA49 & $7.0 \pm 0.8$ & $3.0 \pm 0.7$ & $0.4 \pm 0.4$ \\
ZD1-1 & $8.5 \pm 0.7$ & $2.4 \pm 0.8$ & $0.2 \pm 0.4$ \\
ZD1-2 & $7.1 \pm 1.0$ & $2.2 \pm 0.9$ & $0.3 \pm 0.5$ \\
ZD5-2 & $7.9 \pm 0.9$ & $2.0 \pm 0.8$ & $0.3 \pm 0.5$ \\
ZB1-2-5 & $8.6 \pm 0.7$ & $2.9 \pm 0.9$ & $2.5 \pm 1.0$ \\
J3-2 & $8.4 \pm 0.7$ & $2.1 \pm 0.9$ & $1.2 \pm 0.6$ \\
14BKY-1 & $8.4 \pm 0.8$ & $2.9 \pm 0.9$ & $2.4 \pm 1.0$ \\
\hline
\end{tabular}

Data presented as the means \pm SD (standard deviations) were obtained from 20 plants with two replicates markers between SNP1 and SNP2 and between SNP4 and SNP5. According to a previous report, a closely linked gene downstream of pi21, Os04g0401400 (LOC_ Os04g32890), was associated with inferior eating quality, which hampered the application of the pi21 blast resistance gene in breeding [7]. In this study, the resistant pi21 allele from the donor GKGH was used to replace the corresponding allele in the Kongyu-131 genome, and two rounds of recombinant selection were performed to minimize linkage drag near the target gene. Finally, the quality traits of the updated Kongyu-131 were found to be similar to those of Kongyu-131, which indicated that the linkage drag was effectively removed.

\section{Seedling blast resistance and adult blast resistance}

Rice blast may occur at different stages of rice growth and in different parts of rice. Leaf blast and panicle blast are the most common and most harmful types of blast. However, there is no agreement among reports on whether there is consistency between seedling blast resistance and adult blast resistance [7, 17]. The difference may be attributed to differences in the introduced target R-gene and genetic background. Moreover, leaf and panicle tissues are observed at different developmental stages, and the expression of R-gene has spatiotemporal specificity [18]. Pb1 transcript levels increased during the development of $\mathrm{Pb1}+$ cultivars; this expression pattern accounted for their panicle resistance [19]. Inoue et al. found that $P b 1$ was negatively dependent on at least three QTLs on chromosomes 7, 9 and 11 and positively dependent on one QTL on chromosome 8 in the genome of the rice cultivar Kanto209 [20]. In this study, artificial inoculation at the seedling stage was carried out to identify the rice blast resistance level of the improved line and two parents. The leaf blast resistance level of the improved line was enhanced significantly. The field investigation in Jiamusi, Heilongjiang Province, showed that some Kongyu-131 plants were infected with panicle 

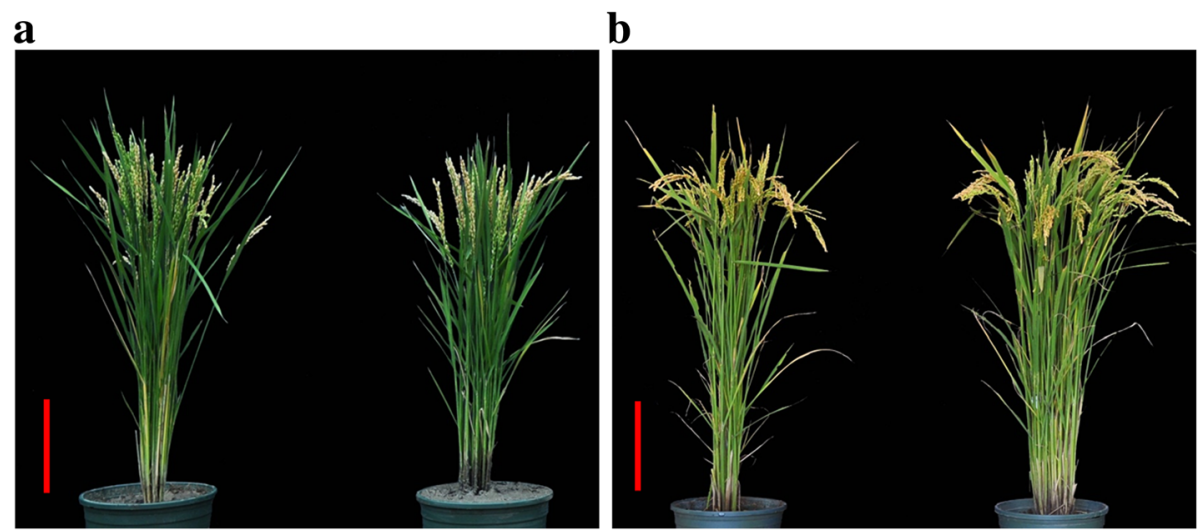

Fig. 5 Plant architecture of Kongyu-131 and the improved line $\mathrm{BC}_{4} \mathrm{~F}_{2}-350 \mathrm{E} 03$. $\mathbf{a}$ in Beijing in 2017 and $\mathbf{b}$ in Jiamusi in 2017; Kongyu-131 (left) and $\mathrm{BC}_{4} \mathrm{~F}_{2}-350 \mathrm{E} 03$ (right). The scale bar represents $20 \mathrm{~cm}$

blast, while the improved line was immune to blast disease. Further validation of the panicle blast resistance under nursery conditions is needed.

\section{Strategies for the loss of resistance to rice blast}

To date, most of the cloned R-genes mediate specific resistance. However, blast-resistant cultivars easily lose resistance due to frequent changes in $M$. grisea pathogenicity $[21,22]$. Therefore, identifying durable disease resistance genes such as $p i 21$ and $P b 1$ for disease resistance breeding has been a goal of breeders for several decades.

In addition to durable blast resistance genes, the complementarity of multiple R-genes can be utilized comprehensively to effectively avoid the defects that accompany single gene-mediated resistance. At present, the introduction of multiple resistance genes into a single variety is widely used by breeders to improve disease resistance $[10,17,23-25]$.
The concept of multiline was well demonstrated in the management of wheat rust diseases [26], and more recently, a transgenic multiline variety for controlling powdery mildew of wheat has been developed [27]. A previous study found that Kongyu-131 contained the resistant Pish gene but lacked almost all other cloned blast resistance genes [13]. The method of improving the Pi21 locus in Kongyu-131 described here could be used to update other blast resistance genes. Then, SPSLs carrying individual blast resistance genes in the genetic background of Kongyu-131 can be developed with nearly identical height, maturity, plant architecture, grain and cooking quality traits and other characteristics. These SPSLs are similar in appearance and genetic constitution but carry different genes for resistance to blast disease. Therefore, the lines can be used to create a multiline variety by mechanically mixing their seeds. This method also offers farmers a way to treat outbreaks of blast disease. Once a line's resistance is overcome in the field,

Table 3 Agronomic performance of Kongyu-131 and the improved line $\mathrm{BC}_{4} \mathrm{~F}_{2}-350$ E03 in three environments

\begin{tabular}{|c|c|c|c|c|c|c|}
\hline \multirow[t]{2}{*}{ Trait } & \multicolumn{2}{|c|}{2017 Beijing } & \multicolumn{2}{|c|}{2017 Jiamusi } & \multicolumn{2}{|c|}{2018 Jiamusi } \\
\hline & KY131 & $\mathrm{BC}_{4} \mathrm{~F}_{2}-350 \mathrm{E} 03$ & KY131 & $\mathrm{BC}_{4} \mathrm{~F}_{2}-350 \mathrm{E} 03$ & KY131 & $\mathrm{BC}_{4} \mathrm{~F}_{2}-350 \mathrm{E} 03$ \\
\hline$\overline{\mathrm{DTH}}$ & $66.2 \pm 0.7$ & $68.9 \pm 1.4^{* *}$ & $103.3 \pm 1.4$ & $103.6 \pm 1.5$ & $102.8 \pm 1.4$ & $103.1 \pm 1.5$ \\
\hline $\mathrm{PH}(\mathrm{cm})$ & $50.2 \pm 0.8$ & $49.7 \pm 1.1$ & $74.0 \pm 3.5$ & $74.7 \pm 3.1$ & $74.3 \pm 4.7$ & $74.2 \pm 3.1$ \\
\hline ETP & $29.1 \pm 1.5$ & $28.4 \pm 2.4$ & $34.7 \pm 3.5$ & $33.5 \pm 4.0$ & $30.7 \pm 4.5$ & $32.2 \pm 4.9$ \\
\hline $\mathrm{PL}(\mathrm{cm})$ & $13.3 \pm 0.5$ & $13.0 \pm 0.8$ & $16.1 \pm 0.6$ & $16.0 \pm 0.7$ & $16.0 \pm 1.7$ & $16.3 \pm 1.2$ \\
\hline NPB & $6.7 \pm 0.8$ & $6.8 \pm 0.6$ & $10.2 \pm 0.9$ & $10.6 \pm 1.2$ & $11.7 \pm 1.5$ & $11.2 \pm 1.0$ \\
\hline GNP & $67.4 \pm 6.2$ & $70.6 \pm 6.8$ & $116.3 \pm 8.1$ & $120.3 \pm 14.1$ & $102.9 \pm 4.7$ & $101.3 \pm 6.3$ \\
\hline SSP (\%) & $94.7 \pm 2.7$ & $93.1 \pm 2.5$ & $94.6 \pm 3.2$ & $93.6 \pm 2.0$ & $95.6 \pm 1.2$ & $95.8 \pm 1.1$ \\
\hline YP (g) & $29.3 \pm 2.7$ & $28.7 \pm 2.4$ & $53.0 \pm 2.3$ & $54.2 \pm 2.8$ & $49.4 \pm 2.3$ & $52.4 \pm 3.5$ \\
\hline TGW (g) & $23.9 \pm 0.3$ & $23.9 \pm 0.8$ & $27.2 \pm 0.6$ & $27.3 \pm 1.0$ & $27.0 \pm 1.0$ & $27.0 \pm 1.0$ \\
\hline GYP (kg) & NA & NA & NA & NA & $3.97 \pm 0.26$ & $4.49 \pm 0.34^{* *}$ \\
\hline
\end{tabular}

Data presented as the means \pm SD (standard deviations) were obtained from 10 plants with three replicates under natural conditions in Beijing and Jiamusi. The planting density was $30 \mathrm{~cm} \times 20 \mathrm{~cm}$, with one plant per hill. GYP data were obtained from plants in 10 plots, and the area per plot was $5.76 \mathrm{~m}^{2}(2.4 \mathrm{~m} \times 2.4 \mathrm{~m})$.

${ }^{* *}$ represents a significant difference at $p \leq 0.01$ based on Student's $t$-test. "NA" means data not available 


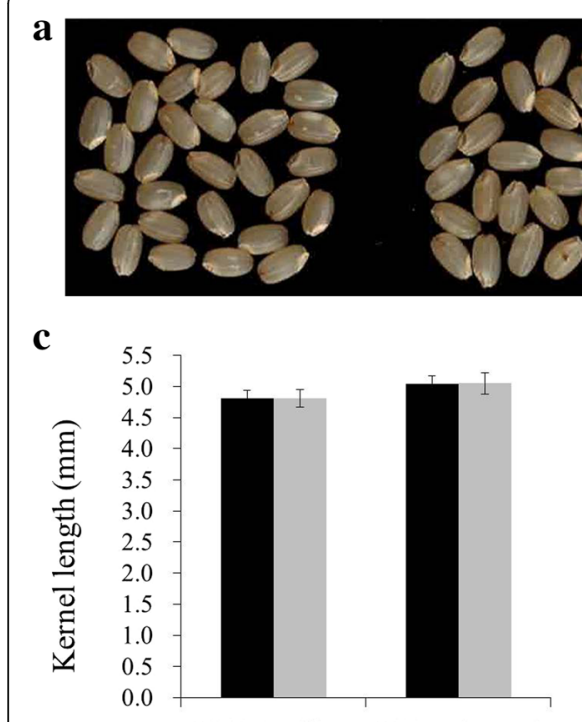

2017 Beijing 2017 Jiamusi

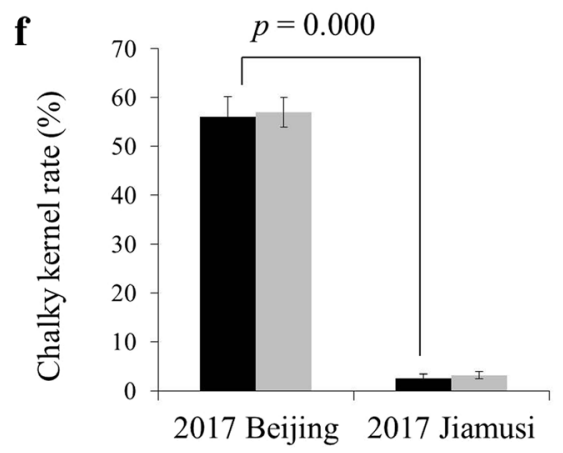

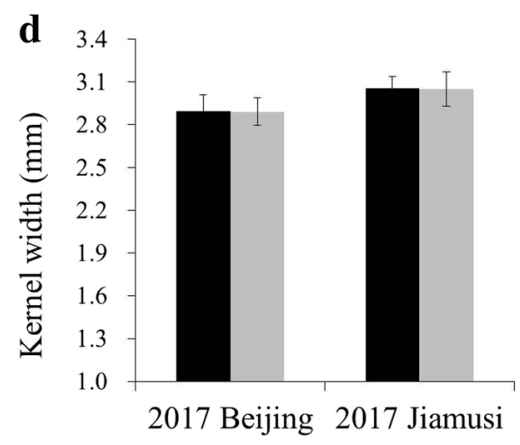

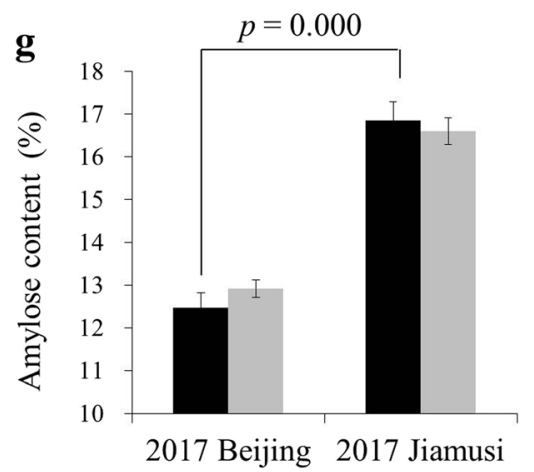

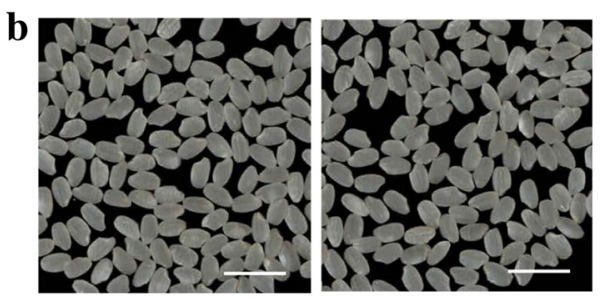
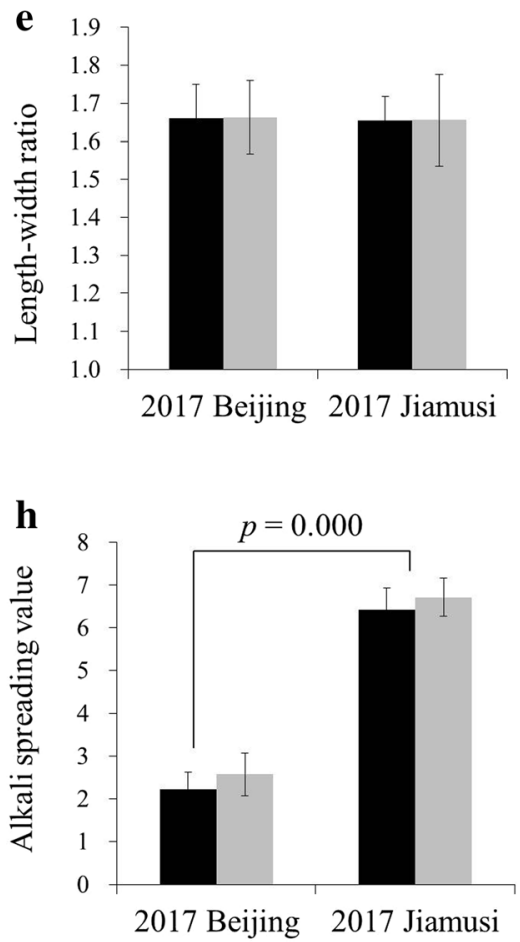

Fig. 6 Comparison of grain quality in the improved line and Kongyu-131. a Performance of the brown rice cultivar. From left to right, Kongyu-131 in Jiamusi in 2017, the SPSL BC $\mathrm{F}_{2}-350$ E03 in Jiamusi in 2017, and the donor GKGH in Beijing in 2017 (normal heading did not occur in Jiamusi in 2017). b Performance of the milled grain. Kongyu-131 (left), $\mathrm{BC}_{4} \mathrm{~F}_{2}-350 \mathrm{E} 03$ (right); the scale bar represents $1 \mathrm{~cm}$. $\mathbf{c}$ Kernel length ( $n=30$ ). $\mathbf{d}$ Kernel width $(n=30)$. e Length-width ratio $(n=30)$. f Chalky kernel rate $(n=500)$. $\mathbf{g}$ Amylose content $(n=4)$. $\mathbf{h}$ Alkali spreading value $(n=14)$. In $\mathbf{c}-\mathbf{h}$, the black bar represents Kongyu-131, and the gray bar represents the improved line $\mathrm{BC}_{4} \mathrm{~F}_{2}-350 \mathrm{E} 03$. Data was presented as the means $\pm \mathrm{SD}$ (standard deviations)

it is easy to analyze its R-genes and replace them with other blast resistance genes.

The large-scale cultivation of an excellent rice variety over the long term tends to cause the loss of blast resistance. Therefore, in addition to the application of Rgenes, it is also necessary to monitor the pathogenic races and virulence gene structure of the $M$. oryzae population in the rice cultivation area to update rice varieties with corresponding genes for blast resistance.

\section{Conclusions}

The cultivation of blast-resistant rice varieties is the most economical and effective method to control rice blast. In this study, an upland rice variety (GKGH) with broad-spectrum resistance to blast disease was used as the donor parent to improve the resistance level of Kongyu-131. The resistant pi21 allele was used to precisely substitute the corresponding allele into Kongyu-131. Five SNP markers in and around pi21 were designed to break the linkage drag by two rounds of recombinant selection on both sides of the target gene. Finally, the newly bred Kongyu-131 exhibited improved blast resistance both in an incubator under artificial inoculation and in natural conditions with no yield or quality penalties. The methods of updating varieties and eliminating linkage drag proposed in this study can also provide a reference for the improvement of other crop varieties.

\section{Methods}

Rice materials

The recurrent parent Kongyu-131 (originated in Japan and introduced into China as an elite rice variety; the seeds were from Lin's lab in the Institute of Genetics 
and Developmental Biology, Chinese Academy of Sciences) is an early-maturity japonica rice variety grown in the high-latitude zone of Heilongjiang Province, China. This variety has strong tillering ability, lodging resistance, and cold tolerance but the defect of high blast susceptibility. Kongyu-131 requires an accumulated temperature of $2330^{\circ} \mathrm{C}$ and produces an average yield of $7684.5 \mathrm{~kg} / \mathrm{ha}$. The donor parent GKGH (originated in China, and the seeds were from Lin's lab in the Institute of Genetics and Developmental Biology, Chinese Academy of Sciences) is an upland rice variety resistant to rice blast, but normal heading does not occur in this variety in Heilongiiang Province due to an unsuitable photoperiod and temperature.

\section{Isolates}

Diseased panicles and leaves of Kongyu-131 were collected from paddy fields of rice production areas in Heilongjiang Province from 2002 to 2006 and used to isolate blast fungus [12]. Five genetically different and representative isolates (ZA49, ZD1-1, ZD1-2, ZD5, and ZB1) were used in this study. In addition, two other strains (J3-2 and 14BKY-1) were isolated from the diseased panicles or leaves of Kongyu-131 from paddy fields in 2013 and 2014, respectively. All 7 isolates were used for the present study.

\section{Resequencing, comparison of Pi21 sequences and SNP marker design}

The Kongyu-131 and GKBR rice varieties were sequenced using a HiSeq 2000 sequencing system (Illumina, USA). We downloaded the Pi21 DNA sequences of Aichi-asahi and Owarihatamochi [7] from GenBank (http://www.ncbi.nlm.nih.gov/genbank) and compared the Pi21 DNA sequences of Kongyu-131, GKGH, Aichi-asahi and Owarihatamochi using DNAMAN software. SNP markers were developed according to the SNPs between Kongyu-131 and GKGH. The SNPs and their flanking 22 24 nt sequences were used to design locus-specific or allele-specific primers, and the amplicons were approximately $50 \sim 100 \mathrm{bp}$ long. Five InDel/SNP markers named SNP1-SNP5 were designed (Table 4). InDel3 was an InDel marker located in Pi21, SNP1 and SNP2 were located upstream of Pi21, and
SNP4 and SNP5 were located downstream of Pi21. SNP2 was close to the $5^{\prime}$-untranslated region (UTR) of Pi21, and SNP4 was close to the $3^{\prime}$-UTR of Pi21. The distance between SNP2 and SNP4 was $4692 \mathrm{bp}$, while the distance between SNP1 and SNP5 was $634 \mathrm{~kb}$.

\section{Population development and line selection by genotyping}

The donor parent GKGH was crossed and backcrossed with the recurrent parent Kongyu-131 to produce a series of populations in Hainan and Guangdong Provinces from 2013 to 2016 (Fig. 7). The $F_{2}$ population was used for QTL analysis. Two lines hosting the target gene were selected from the $\mathrm{BC}_{2} \mathrm{~F}_{1}$ population according to the genotype at InDel3. The line named $\mathrm{BC}_{3} \mathrm{~F}_{1}-08 \mathrm{G} 02$, with crossover on one side of the target gene, was selected from the backcross progenies of the two lines. The line named $\mathrm{BC}_{3} \mathrm{~F}_{2}-669 \mathrm{E} 10$, with crossover on the other side of the target gene, was selected from the selfed progenies. To further eliminate the nontarget chromosomal fragments from the background, $\mathrm{BC}_{3} \mathrm{~F}_{2}$ 669E10 was crossed with Kongyu-131, and a line named $\mathrm{BC}_{4} \mathrm{~F}_{1}-30 \mathrm{~B} 07$, which hosted the target gene and the minimum number of nontarget segments, was selected from the progenies. Ultimately, a line named $\mathrm{BC}_{4} \mathrm{~F}_{2}-$ $350 \mathrm{E} 03$, with only one small chromosome fragment carrying the target gene, was selected from a large $\mathrm{BC}_{4} \mathrm{~F}_{2}$ population derived from $\mathrm{BC}_{4} \mathrm{~F}_{1}-30 \mathrm{~B} 07$.

\section{Inoculation and phenotyping}

The $F_{2}$ population (141 lines) derived from Kongyu-131 and GKGH was seeded into a specially made 96-well PCR plate with a hole $(\Phi=2.5 \mathrm{~mm})$ at the bottom. One seed was placed in each well with the embryo pointing upward, and seedlings at the 3 4 leaf stage were placed in a climatic chamber for inoculation. Inoculations were performed by spraying conidial suspensions $\left(5 \times 10^{5}\right.$ spores $/ \mathrm{ml}$ ) onto the leaves until run-off occurred. Before inoculation, $0.05 \%$ Tween 20 was added to the suspension to increase the adhesion of the spores to the plant. The relative humidity was maintained at $100 \%$ for $24 \mathrm{~h}$ of dark treatment at $25-28^{\circ} \mathrm{C}$ before transferring the plants back to the greenhouse. After 7 days, the lesion degree (LD) of the rice leaves was scored from 0 to 9

Table 4 Sequences and positions of the SNP markers developed for the selection of pi21

\begin{tabular}{lllll}
\hline Markers & Chr. & Position (IRGSP1.0) & Forward primer (5'-3') & Reverse primer (5'-3') \\
\hline SNP1 & 4 & $19,354,482$ & TGCACCAGTATTAACAATTGA & CCATAAAACTAGATATAGAGC \\
SNP2 & 4 & $19,855,434$ & TGCTAATCCGGAATCTCGAC & TTCGAACATAAGGTGGTCGAC \\
InDel3 & 4 & $19,856,847$ & GATCCTCATCGTCGACGTCT & TTGCAGTCCTCCGGAGGCTTCT \\
SNP4 & 4 & $19,860,126$ & TGGGATAGTCATCAATGGTGC & CCATTGATGAGTCTATTGTAG \\
SNP5 & 4 & ATAATGGGATGAGACCCATC & TGGGATCCAGATTCGTAGTCTC \\
\hline
\end{tabular}




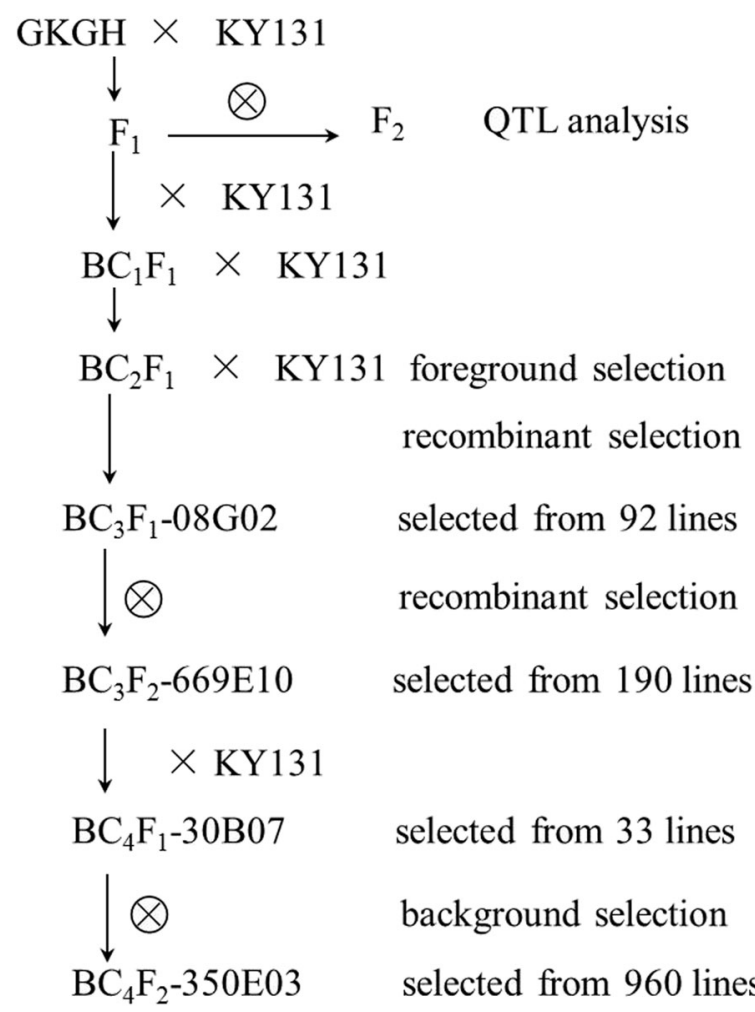

Fig. 7 Procedure for population development

according to the Standard Evaluation System of the International Rice Research Institute (IRRI) [28]. The lines with scores of $0-3$ were considered to be resistant to blast disease, while those with scores of 7-9 were considered to be susceptible to blast disease. The methods for evaluating the resistance of the improved line $\mathrm{BC}_{4} \mathrm{~F}_{2}-350 \mathrm{E} 03$ and two parents were the same as those described above, with two duplications. Each duplication included 7 specially made PCR plates, with Kongyu-131 in rows $A$ and $E$, the donor parent GKGH in rows $\mathrm{D}$ and $\mathrm{H}$, and $\mathrm{BC}_{4} \mathrm{~F}_{2}-350 \mathrm{E} 03$ in the other 4 rows. Seven isolates (ZA49, ZD1-1, ZD1-2, ZD5, ZB1, J3-2 and 14BKY-1) were used for inoculation.

\section{Genotyping and data analysis}

DNA extraction, PCR and high-resolution melting (HRM) analysis were carried out as described by Feng et al. [14]. According to the physical position of the cloned blast resistance genes and the SNPs between Kongyu131 and GKGH, 12 SNP markers tightly linked to corresponding blast resistance genes were developed to genotype the $F_{2}$ population. A chi-square test was used to analyze the $F_{2}$ population segregation data. Marker-trait association analysis was performed using Mapmaker/ QTL 1.1b [29] with a threshold logarithm of the odds (LOD) score of 2.0.

\section{Evaluation of agronomic traits}

The improved line $\mathrm{BC}_{4} \mathrm{~F}_{2}-350 \mathrm{E} 03$ and Kongyu-131 were planted in Jiamusi (E130 57', N46 23'), Heilongjiang Province, and in Beijing (E116 $30^{\prime}, \mathrm{N}^{\circ} 9^{\circ} 9^{\prime}$ ) with three replicates. Each replicate consisted of 8 rows with 12 plants per row. The plant spacing was $20 \mathrm{~cm}$ within each row and $30 \mathrm{~cm}$ between adjacent rows, and the field management was the same as that used in local paddy fields. At the time of harvest, 10 plants in the middle of each plot were selected randomly for phenotypic investigation; every selected plant had to meet the condition that its surrounding 8 plants exhibited normal growth vigor. Days to heading $(\mathrm{DTH})$ was calculated from the time of seed soaking to the time when $50 \%$ of plants flowered in the plots. Plant height $(\mathrm{PH})$, effective tillers per plant (ETP), panicle length (PL), number of primary branches per panicle (NPB), grain number per panicle (GNP), thousand-grain weight (TGW), yield per plant (YP), grain yield per plot (GYP) and moisture content of the grain were investigated. The YP and GYP at a moisture content of $15 \%$ and the seed setting percentage (SSP) were calculated.

\section{Evaluation of quality traits}

To assay the grain characteristics, ten fully filled grains from each plot were randomly selected to measure kernel length (KL) and kernel width (KW) using a Vernier caliper. The length-to-width ratio (LWR) was calculated as grain length divided by grain breadth. One hundred fully filled grains were randomly selected with 5 replicates to determine the chalky kernel rate (CKR). The alkali spreading value (ASV) was tested by soaking seven whole-milled grains of the improved line and Kongyu- 131 in $10 \mathrm{ml}$ of $1.7 \% \mathrm{KOH}$ arranged with equal spacing in Petri plates. The Petri plates were kept at $30^{\circ} \mathrm{C}$ for $24 \mathrm{~h}$; thereafter, the grains were individually scored on a scale of $1-7$ as described by Khanna et al. [11]. The amylose content (AC) was measured as described by Tian et al. [30] with four replicates and two parallel measurements.

Experimental research on plants in this study complied with institutional, national, or international guidelines. Field studies were conducted in accordance with local legislation. All the rice populations in this study were developed by technicians in our laboratory with crossing or selfing, and the materials were non-transgenic plants, no permissions and/or licenses were required.

\section{Abbreviations}

AC: Amylose content; ASV: Alkali spreading value; CKR: Chalky kernel rate; DTH: Days to heading; ETP: Effective tillers per plant; GNP: Grain number per panicle; GYP: Grain yield per plot; HRM: High-resolution melting; KL: Kernel length; KW: Kernel width; LD: Lesion degree; LWR: Length-to-width ratio; MAS: Marker-assisted selection; NPB: Number of primary branches per panicle; PH: Plant height; PL: Panicle length; QTL: Quantitative trait locus; RRPG: Recovery ratio of recurrent parent genome; SNP: Single nucleotide polymorphism; SPSL: Single point substitution line; SSP: Seed setting percentage; TGW: Thousand-grain weight; UTR: Untranslated region; YP: Yield per plant 


\section{Acknowledgments}

The authors would like to thank Yu Shen and Jiaxin Liu (Institute of Genetics and Developmental Biology, Chinese Academy of Sciences, Beijing, China) for their kind help.

\section{Authors' contributions}

SYL designed the experiments. XMF carried out the genotyping and evaluation of agronomic traits, performed the statistical analysis and wrote the manuscript. $\mathrm{KXL}, \mathrm{JZN}, \mathrm{XHZ}, \mathrm{CW}$, and RSW were involved in the marker development and validation (including resequencing, bioinformatic analysis, HRM). WQZ participated in the evaluation of agronomic traits. GQJ and QBY performed rice hybridization and field management. All authors read and approved the final manuscript.

\section{Funding}

This work was funded by the "Strategic Priority Research Program" of the Chinese Academy of Sciences (No. XDA08030102-1) and Talent Introduction Subject of the State Key Laboratory of Plant Genomics, Institute of Genetics and Developmental Biology, University of Chinese Academy of Sciences (2014C0227-01).

\section{Availability of data and materials}

The dataset supporting the conclusions of this article is included within this article.

\section{Ethics approval and consent to participate}

Not applicable.

\section{Consent for publication}

Not applicable.

\section{Competing interests}

The authors declare that they have no competing interests.

\section{Author details}

${ }^{1}$ State Key Laboratory of Plant Genomics, Institute of Genetics and Developmental Biology, Chinese Academy of Sciences, Beijing 100101, China ${ }^{2}$ Guangdong Provincial Bioengineering Institute, Guangzhou Sugarcane Industry Research Institute, Guangzhou 510316, China. ${ }^{3}$ University of Chinese Academy of Sciences, Beijing 100039, China.

\section{Received: 14 January 2019 Accepted: 4 June 2019}

\section{Published online: 11 June 2019}

\section{References}

1. Skamnioti P, Gurr SJ. Against the grain: safeguarding rice from rice blast disease. Trends Biotechnol. 2009:27:141-50.

2. Ashkani S, Rafii MY, Shabanimofrad M, Ghasemzadeh A, Ravanfar SA, Latif MA. Molecular progress on the mapping and cloning of functional genes for blast disease in rice (Oryza sativa L.): current status and future considerations. Crit Rev Biotechnol. 2016:36:353-67.

3. Wang ZX, Yano M, Yamanouchi U, Iwamoto M, Monna L, Hayasaka H, Katayose Y, Sasaki T. The Pib gene for rice blast resistance belongs to the nucleotide binding and leucine-rich repeat class of plant disease resistance genes. Plant J. 1999;19:55-64.

4. Li W, Zhu Z, Chern M, Yin J, Yang C, Ran L, Cheng M, He M, Wang K, Wang $J$, et al. A natural allele of a transcription factor in rice confers broadspectrum blast resistance. Cell. 2017:170:114-26.

5. Zhou X, Liao H, Chern M, Yin J, Chen Y, Wang J, Zhu X, Chen Z, Yuan C, Zhao $W$, et al. Loss of function of a rice TPR-domain RNA-binding protein confers broad-spectrum disease resistance. Proc Natl Acad Sci U S A 2018:115:3174-9.

6. Chen X, Shang J, Chen D, Lei C, Zou Y, Zhai W, Liu G, Xu J, Ling Z, Cao G, Ma BT, Wang YP, Zhao XF, Li SG, Zhu LH. A B-lectin receptor kinase gene conferring rice blast resistance. Plant J. 2006;46:794-804.
7. Fukuoka S, Saka N, Koga H, Ono K, Shimizu T, Ebana K, Hayashi N, Takahashi A, Hirochika $H$, Okuno K, Yano M. Loss of function of a proline-containing protein confers durable disease resistance in rice. Science. 2009;325:998-1001.

8. Zhao H, Wang X, Jia Y, Minkenberg B, Wheatley M, Fan J, Jia MH, Famoso A, Edwards JD, Wamishe $Y$, et al. The rice blast resistance gene Ptr encodes an atypical protein required for broad-spectrum disease resistance. Nat Commun. 2018. https://doi.org/10.1038/s41467-018-04369-4.

9. Wu YY, Yu L, Pan CH, Dai ZY, Li YH, Xiao N, Zhang XX, Ji HJ, Huang NS, Zhao BH, Zhou CH, Liu GQ, Liu XJ, Pan XB, Liang CZ, Li AH. Development of near-isogenic lines with different alleles of Piz locus and analysis of their breeding effect under Yangdao 6 background. Mol Breed. 2016;36(2):12.

10. Jiang H, Feng Y, Bao L, Li X, Gao G, Zhang Q, Xiao J, Xu C, He Y. Improving blast resistance of Jin $23 \mathrm{~B}$ and its hybrid rice by marker-assisted gene pyramiding. Mol Breed. 2012;30:1679-88.

11. Khanna A, Sharma V, Ellur RK, Shikari AB, Krishnan SG, Singh UD, Prakash G, Sharma TR, et al. Development and evaluation of near-isogenic lines for major blast resistance gene(s) in basmati rice. Theor Appl Genet. 2015;128:1243-59.

12. Song $C Y$, Wang $G L$, Xin AH, Cong WB. Analysis on kinds of rice blast races in Kongyu-131 and its reasons of pathologic reaction. Heilongjiang Agricultural Sciences. 2007;1:41-2.

13. Zhang $X H$, Feng $X M$, Lin SY. Scanning for pi loci and rebuilding an improved genome of elite rice variety Kongyu-131. Chin Bull Bot. 2017; 52:30-42.

14. Feng XM, Wang C, Nan JZ, Zhang XH, Wang RS, Jiang GQ, Yuan QB, Lin SY. Updating the elite rice variety Kongyu 131 by improving the Gnla locus. Rice. 2017:10:35

15. Lind SY, Takashi T, Nishimura A. Update for elite japonica variety. Paper presented at the international symposium on rice research in the era of global warming, Taiwan agriculture research institute. Taiwan. 2009:5-11.

16. Lin SY. Method of plant genome design, method of creating new cultivar and new cultivar. US Patent. 2014:8(889):948 B2.

17. Xiao N, Wu Y, Pan C, Yu L, Chen Y, Liu G, Li Y, Zhang X, Wang Z, Dai Z. Improving of rice blast resistances in Japonica by pyramiding major $\mathrm{R}$ genes. Front Plant Sci. 2017. https://doi.org/10.3389/fpls.2016.01918.

18. Wang L, Xie W, Chen Y, Tang W, Yang J, Ye R, Liu L, Lin Y, Xu C, Xiao J, et al. A dynamic gene expression atlas covering the entire life cycle of rice. Plant J. 2010;61:752-66.

19. Hayashi $N$, Inoue $H$, Kato $T$, Funao $T$, Shirota M, Shimizu T, Kanamori H, Yamane H, Hayano-Saito Y, Matsumoto T, Yano M, Takatsuji H. Durable panicle blast-resistance gene $\mathrm{Pb} 1$ encodes an atypical CC-NBS-LRR protein and was generated by acquiring a promoter through local genome duplication. Plant J. 2010;64(3):498-510.

20. Inoue H, Nakamura M, Mizubayashi T, Takahashi A, Sugano S, Fukuoka S, Hayashi N. Panicle blast 1 (Pb1) resistance is dependent on at least four QTLs in the rice genome. Rice. 2017:10:36.

21. Dean RA, Talbot NJ, Ebbole DJ, Farman ML, Mitchell TK, Orbach MJ, Thon M Kulkarni $\mathrm{R}$, Xu JR, Pan $\mathrm{H}$, et al. The genome sequence of the rice blast fungus Magnaporthe grisea. Nature. 2005;434:980-6.

22. Ebbole DJ. Magnaporthe as a model for understanding host-pathogen interactions. Annu Rev Phytopathol. 2007:45:437-56.

23. Fukuoka S, Saka N, Mizukami Y, Koga H, Yamanouchi U, Yoshioka Y, Hayash N, Ebana K, Mizobuchi R, Yano M. Gene pyramiding enhances durable blast disease resistance in rice. Sci Rep. 2015. https://doi.org/10.1038/srep07773.

24. Pradhan SK, Nayak DK, Mohanty S, Behera L, Barik SR, Pandit E, Lenka S, Anandan A. Pyramiding of three bacterial blight resistance genes for broadspectrum resistance in Deepwater rice variety, Jalmagna. Rice. 2015;8:51.

25. Suh JP, Jeung JU, Noh TH, Cho YC, Park SH, Park HS, Shin MS, Kim CK, Jena KK. Development of breeding lines with three pyramided resistance genes that confer broad-spectrum bacterial blight resistance and their molecular analysis in rice. Rice. 2013;6:5.

26. Luthra JK, Rao MV. Multiline cultivars-how their resistance influence leaf rust disease in wheat. Euphytica. 1979;28(1):137-44.

27. Brunner S, Stirnweis D, Diaz Quijano C, Buesing G, Herren G, Parlange F, Barret P, Tassy C, Sautter C, Winzeler M, Keller B. Transgenic Pm3 multilines of wheat show increased powdery mildew resistance in the field. Plant Biotechnol J. 2012:10:398-409. 
28. International Rice Research Institute (IRRI). Standard evaluation system for rice International Rice Research Institute, 4th edn. Manila, Philippines, 1996;p 56.

29. Lincoln S, Daly M, Lander E. Constructing genetics maps with MAPMAKER /EXP 3.0. Whitehead institute technical report, 3rd. Cambridge,

Massachusetts: Whitehead Technical Institute; 1992.

30. Tian Z, Qian Q, Liu Q, Yan M, Liu X, Yan C, Liu G, Gao Z, Tang S, Zeng

$D$, et al. Allelic diversities in rice starch biosynthesis lead to a diverse array of rice eating and cooking qualities. Proc Natl Acad Sci U S A. 2009;106:21760-5.

\section{Publisher's Note}

Springer Nature remains neutral with regard to jurisdictional claims in published maps and institutional affiliations.

Ready to submit your research? Choose BMC and benefit from:

- fast, convenient online submission

- thorough peer review by experienced researchers in your field

- rapid publication on acceptance

- support for research data, including large and complex data types

- gold Open Access which fosters wider collaboration and increased citations

- maximum visibility for your research: over $100 \mathrm{M}$ website views per year

At $\mathrm{BMC}$, research is always in progress.

Learn more biomedcentral.com/submissions 